\title{
Urachal Cyst, a Rare Cyst with Multiple Complications
}

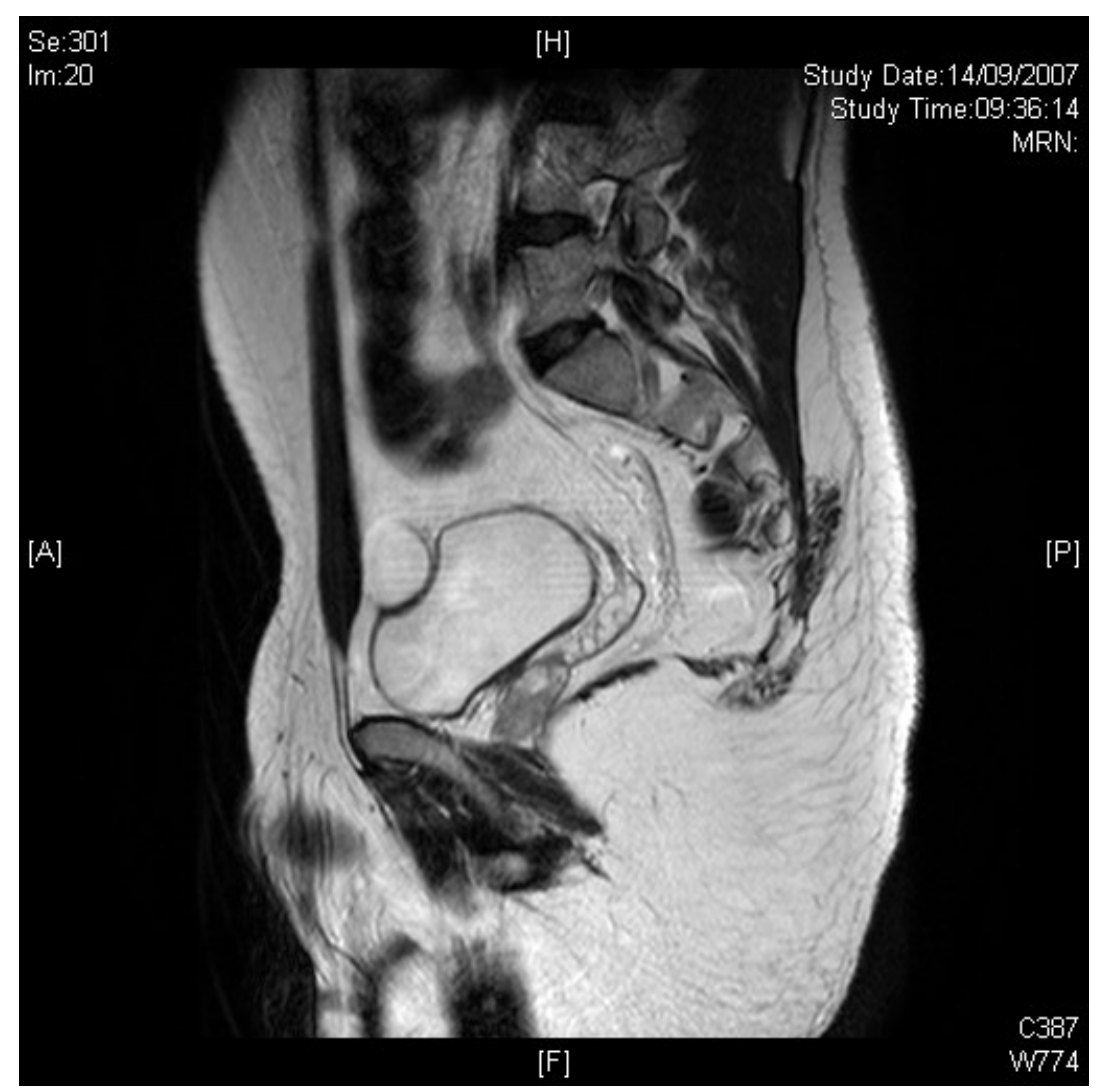

MRI pelvis demonstrates a unilocular cyst, $2.5 \mathrm{~cm}$ in diameter, indenting the bladder dome.

Amr Hawary* and Peter Duffy

Lancaster Royal Infirmary, U.K.

E-mail: amrhawary@hotmail.com

Received December 19, 2007; Revised February 2, 2008; Accepted February 7, 2008; Published February 25, 2008

Urachal cysts are rare, can be one of the forgotten causes of abdominal pain, and can present as adenocarcinoma of the bladder, along with many other presentations. There is a real need for physicians, general surgeons, and urologists to be acquainted with the different presentations and management of this rare condition. 
KEYWORDS: urachal, anomalies, cyst, adenocarcinoma

The image above is from a 24-year-old, male patient who presented to the urology clinic with a history of recurrent episodes of paraumbilical pain and dysuria. IVU and renal ultrasound were normal. This axial MRI study showed a thin-walled cystic lesion of $2.5-\mathrm{cm}$ diameter, indenting the dome of the bladder. It had no communication to the small bowel mesentery.

The diagnosis of urachal cyst was reached.

Urachal cysts are usually symptomless, but can present in a variety of ways, including recurrent urinary tract infections, macroscopic hematuria and hypogastric midline tenderness often associated with a mass, umbilical discharge, and even peritonitis. In children, urachal cysts are common presentations, while in adults, infected urachal sinuses are seen more frequently[1].

Surgical excision of urachal cysts with a bladder cuff excision is recommended to avoid recurrence or development of adenocarcinoma of the bladder in unresected tissue[2].

\section{REFERENCES}

1. Iuchtman, M., Rahav, S., Zer, M., Mogilner, J., and Siplovich, L. (1993) Management of urachal anomalies in children and adults. Urology 42(4), 426-430.

2. Cilento, B.G. Jr, Bauer, S.B., Retik, A.B., Peters, C.A., Atala, A. (1998) Urachal anomalies: defining the best diagnostic modality. Urology 52, 120-122.

This article should be cited as follows:

Hawary, A. and Duffy, P. (2008) Urachal cyst, a rare cyst with multiple complications. TheScientificWorldJOURNAL 8, 237238. DOI 10.1100/tsw.2008.45. 


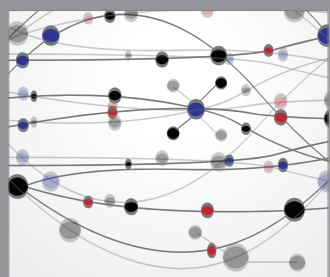

The Scientific World Journal
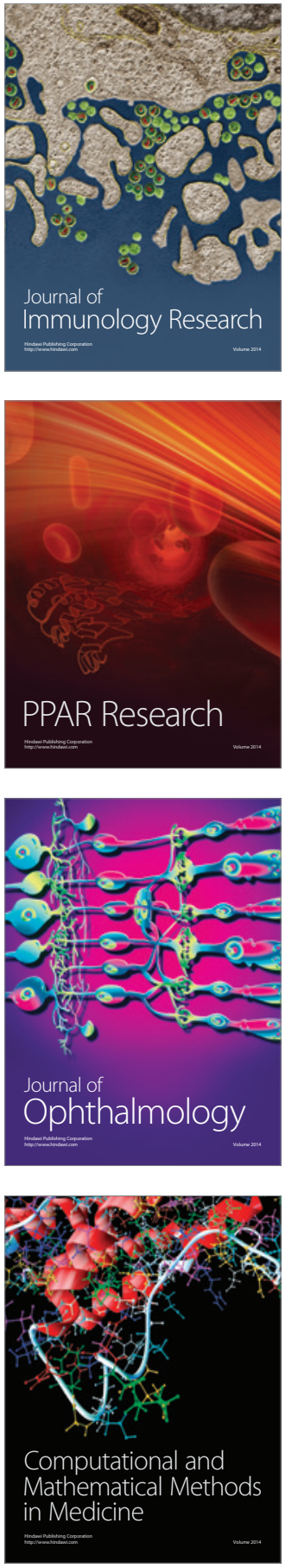

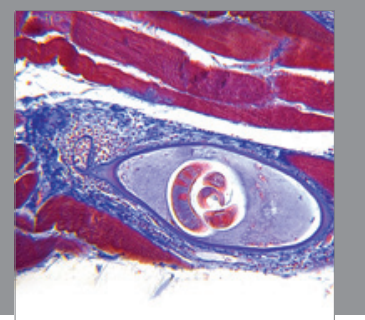

Gastroenterology

Research and Practice
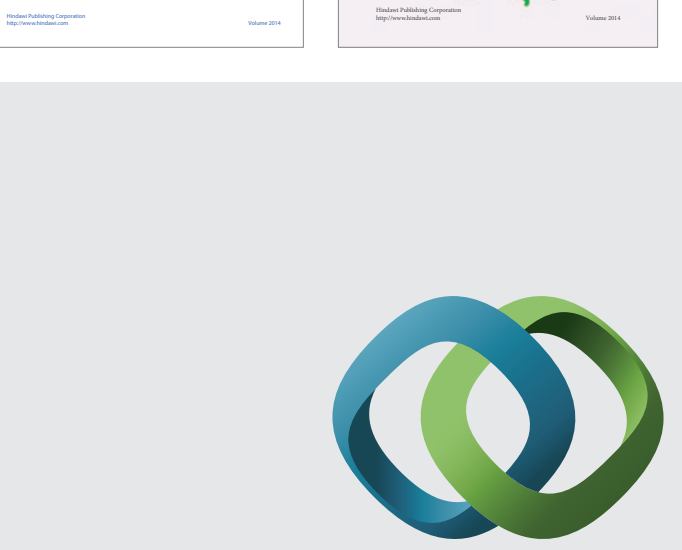

\section{Hindawi}

Submit your manuscripts at

http://www.hindawi.com
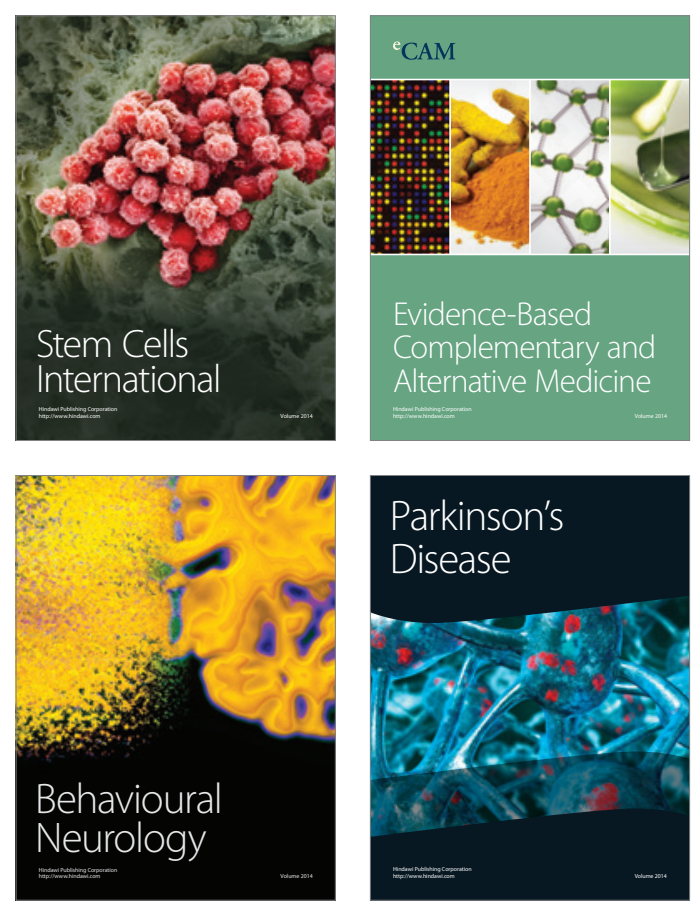

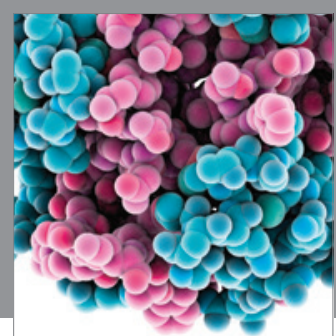

Journal of
Diabetes Research

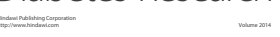

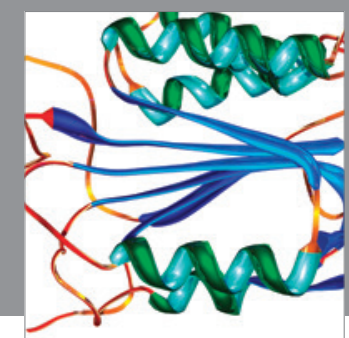

Disease Markers
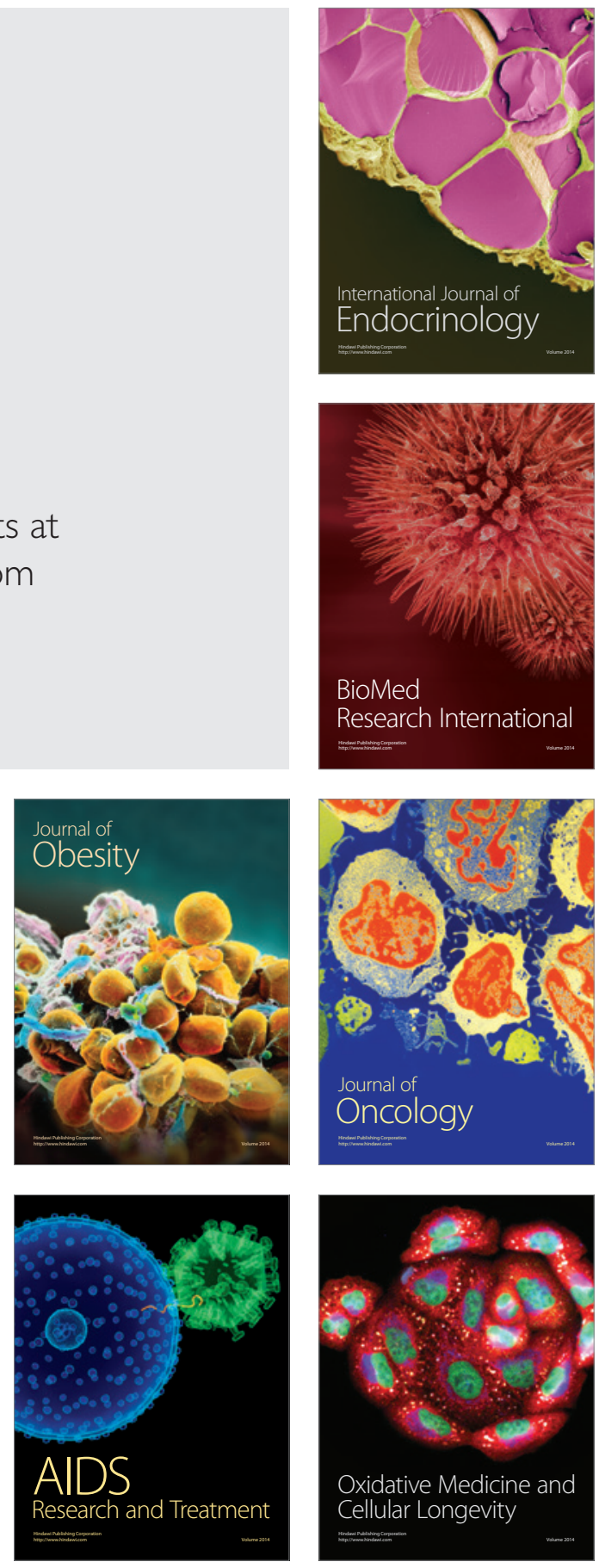